\title{
PUBLIC AWARENESS ABOUT DIABETES: CROSS SECTIONAL STUDY OF LITHUANIA'S RESIDENTS
}

\author{
Lina Jaruseviciene ${ }^{1}$, Leonas Valius ${ }^{1}$, Alminas Jarasunas ${ }^{2}$, Gediminas Jarusevicius ${ }^{3}$ \\ 'Department of Family Medicine, Lithuanian University of Health Sciences, Kaunas, Lithuania \\ ${ }^{2}$ Novo Nordisk Pharma UAB, Vilnius, Lithuania \\ ${ }^{3}$ Department of Cardiology, Lithuanian University of Health Sciences, Kaunas, Lithuania
}

\section{SUMMARY}

Background: Type 2 diabetes is a growing health problem globally; however, awareness about diabetes remains low.

Aim: To assess the public perception of diabetes - how much does the public know about it? What are the beliefs about this challenging issue?

Methods: A public opinion survey was performed in April 2012. Interviews with a random sample of 1,002 residents of Lithuania aged 16-74 were conducted in the households of the respondents. This sample took into account age, sex, education, employment, family status, and the size of the residential location. The topics covered by the 15-item questionnaire used for these interviews concerned the perceived severity of different health conditions and the respondents' knowledge of diabetes risk factors and normal glycemic indicators as well as their perceptions related to diabetes and insulin.

Results: More than half $(56.3 \%)$ of respondents had previously undergone the glycemic control test, $33.8 \%$ of study participants were familiar with the normal parameters of glycemia. Diabetes was ranked fourth among 13 health problems (the top three were attributed to malignancies, AIDS and mental illnesses). The highest score of all risk factors for developing diabetes was attributed to obesity; however, obesity was never mentioned in associating with diabetes by participants. The perceptions people had about diabetes revealed marginally medicalized images of this health condition.

Conclusions: Study findings suggest the potential social stigmatization of diabetes and encourage looking for new ways in approaching the community as well as individual diabetic patients in regard to the issue of diabetes.

Key words: diabetes, public opinion, diabetes risk factors, diabetes perception, health literacy

Address for correspondence: L. Jaruseviciene, Department of Family Medicine, Lithuanian University of Health Sciences, Mickeviciaus 9 , Kaunas, Lithuania. E-mail: ljaruseviciene@gmail.com

\section{INTRODUCTION}

Type 2 diabetes is a growing health problem globally (1). Health care is accessible to most patients with type 2 diabetes. Nonetheless, the outcomes are frequently unsatisfactory (2). Studies indicate that poor health literacy is among the important factors influencing health outcomes in diabetic patients $(3,4)$, although such trends are not consistent (5). Nevertheless, strategies aimed at improving the knowledge patients have about diabetes are particularly important for enhancing their health outcomes (6).

The low health literacy of lay people with regard to non-chronic illnesses can also negatively affect their health. Performed studies indicate that the level of health literacy affects people's decisions and actions as well as their ability to embrace a healthy lifestyle and access the most appropriate form of health care $(7,8)$. Thus the health literacy of people strongly influences the prevention and management of chronic illnesses (9).

Greater literacy amongst the population about interpreting diabetes symptoms may improve the use of health care (10) and, eventually, positively affect community health outcomes. Low awareness about diabetes, in contrast, prevents a part of the population with diabetes symptoms from approaching healthcare institutions and receiving adequate health care on a timely basis (10). Taking into account the late-appearing symptoms of diabetes, community awareness about preventive laboratory tests that help to diagnose the disease at early stage is of the great importance. Research indicates that application of evidence based interventions among people with prediabetes can prevent or delay the onset of diabetes $(11,12)$. Although an epidemic of diabetes is accelerating around the world, awareness of this disease remains low. For example, a study performed in 2010 in China found that only $12.9 \%$ of diabetic residents knew about their condition (13).

Low awareness about this chronic illness might correspond with the perception people have about it as low risk. Research suggest that risk perception regarding the development of diabetes is rather low among lay people as well as among health professionals, and their correlation with the risk of developing type 2 diabetes is weak (14-16). Similar trends were found while investigating the risk perception about diabetes complications in people already diagnosed with type 2: a study by Calvin et al. (17) demonstrated low perception regarding diabetes complications among people with type 2 diabetes, which was not in line with their physiologically indicated risk.

The prevalence of type 2 diabetes in Lithuania is increasing. Therefore, the healthcare system has taken precautions to extend its services in order to achieve better health outcomes in diabetic patients. However, not much is known about the public's awareness regarding the risk factors for developing diabetes and, in general, about its perception of this condition. It is difficult to match preventive strategies to the real needs of the population 
without such information. Thus the objectives of this survey were to assess the public's perceptions, knowledge and potential beliefs regarding diabetes.

\section{MATERIALS AND METHODS}

This article is based on a national, representative survey conducted in April 2012. The random multilevel selection of 16 to 74 year-old Lithuanian residents was carried out according to age, sex, education, employment, marital status, and size of residential location. Each respondent was interviewed in his/her household during the last two weeks of April in 2012.

There were 1,435 residents of Lithuania selected for this survey. Of these residents, 174 were not at home during the time of the survey and, of the remaining 1,261 residents, 259 refused to participate in the survey. Thus there were 1,002 participants who did participate in the survey, constituting a response rate of $79.6 \%$. UAB RAIT, a market analysis and survey agency, selected and interviewed the respondents for this study. The study participants were informed in writing about the selection procedure, purpose of the questionnaire and planned publications. They were also guaranteed full confidentiality. The socio-demographic characteristics of the respondents did not differ significantly from non-respondents. The socio-demographic characteristics of the respondents are presented in Table 1 .

A 15-item questionnaire was used for the interviews in this cross-sectional study. Only minor revisions were made for the final version of the questionnaire after the pilot testing of 21 people. The Bioethics Committee of the Lithuanian University of Health Sciences determined that it was not necessary to obtain the consent of the committee for this kind of study.

The questionnaire addressed the following issues:

- socio-demographic data;

- estimation of the severity of different chronic conditions;

- participants' first associations relevant to diabetes and insulin (self-generated responses);

- respondents' knowledge of symptoms related to diabetes and normal glycemic indicators (self-generated responses);

- perceived importance of different risk factors to the incidence of diabetes.

All self-generated answers were coded before they were entered into the data base. The Statistical Package for the Social Sciences for Windows (SPSS), version 19.0, was employed to code and analyse the resulting data. Chi-square tests were used to investigate the statistical correlation between the categorical variables. The statistical significance level was set at $\mathrm{p}<0.05$.

\section{RESULTS}

\section{Severity Perception Regarding Chronic Health Con- ditions}

Respondents were presented 13 chronic health problems and requested to rank them according to their severity. Respondents were asked to select up to 3 chronic illnesses. Malignancies, AIDS and mental illnesses were selected as the most serious health conditions. Diabetes was rated as the fourth one (Table 2).
Table 1. Socio-demographic characteristics of respondents $(N=1,002)$

\begin{tabular}{|l|c|c|}
\hline & $\mathrm{n}$ & $\%$ \\
\hline Gender & 478 & 47.7 \\
\hline Male & 524 & 52.3 \\
\hline Female & 314 & 31.3 \\
\hline Age (years) & 373 & 37.2 \\
\hline $16-34$ & 315 & 31.4 \\
\hline $35-54$ &
\end{tabular}

\begin{tabular}{|l|l|l|}
\hline \multicolumn{2}{|l|}{ Education } \\
\hline Basic or less & 185 & 18.5 \\
\hline General (secondary school) & 293 & 29.3 \\
\hline Further education & 248 & 24.8 \\
\hline Higher (university) & 274 & 27.4 \\
\hline
\end{tabular}

\begin{tabular}{|l|c|c|}
\hline Marital status \\
\hline Married & 565 & 56.4 \\
\hline Single & 202 & 20.2 \\
\hline Divorced & 91 & 9.1 \\
\hline Widow(er) & 92 & 9.2 \\
\hline Family without registered marriage & 52 & 5.2 \\
\hline
\end{tabular}

\begin{tabular}{|l|c|c|}
\hline \multicolumn{2}{|l|}{ Employment } \\
\hline Employed & 520 & 51.9 \\
\hline $\begin{array}{l}\text { Unemployed (including students, } \\
\text { retired people, etc.) }\end{array}$ & 482 & 48.1 \\
\hline
\end{tabular}

\begin{tabular}{|l|l|l|}
\hline \multicolumn{2}{|l|}{ Monthly income per person in the household* } \\
\hline Up to 500 Litas & 149 & 18.0 \\
\hline 501 to 1,000 Litas & 439 & 53.1 \\
\hline More than 1,000 Litas & 239 & 28.9 \\
\hline Nationality \\
\hline Lithuanian \\
\hline Other nationality & 897 & 89.7 \\
\hline Size of residential location & 103 & 10.3 \\
\hline Up to 2,000 residents & 324 & 32.4 \\
\hline 2,000-180,000 residents & 350 & 35.0 \\
\hline More than 180,000 residents & 327 & 32.7 \\
\hline
\end{tabular}

*1 Litas $=0.29 €$

\section{Risk Perception of Different Risk Factors and Life- style Components}

The respondents of this study were presented 18 risk factors and lifestyle components and asked to rank each of them according to their risk of developing type 2 diabetes (Table 3 ). These comprised a mix of well known risk factors for diabetes (e.g. low physical activity) and other lifestyle components that are not commonly associated with diabetes (e.g. substance use). Respondents used a 6-point scale from 0 (no risk at all) to 5 (very high risk).

Respondents scored all the listed risk factors from 2 to 4 points. They attributed the highest risk to obesity and being overweight -3.97 points \pm 0.046 . The options that were scored 
Table 2. The most serious health conditions as viewed by Lithuanian residents $(N=1,002)$

\begin{tabular}{|l|c|c|}
\hline \multirow{2}{*}{ Conditions } & \multicolumn{2}{|c|}{ Number of respondents } \\
\cline { 2 - 3 } & $\mathbf{n}^{1}$ & $\%$ \\
\hline Malignancies & 836 & 83.4 \\
\hline AIDS & 670 & 66.9 \\
\hline Mental illnesses & 361 & 36.0 \\
\hline Diabetes & 295 & 29.4 \\
\hline $\begin{array}{l}\text { Ischemic heart disease (angina } \\
\text { pectoris, myocardial infarction) }\end{array}$ & 211 & 21.1 \\
\hline Tuberculosis & 167 & 16.6 \\
\hline Hypertension & 153 & 15.3 \\
\hline Chronic joint conditions & 37 & 3.7 \\
\hline Bronchial asthma & 28 & 2.8 \\
\hline Peptic ulcer & 24 & 2.4 \\
\hline Chronic kidney conditions & 19 & 1.9 \\
\hline Chronic eye conditions & 12 & 1.2 \\
\hline Chronic skin conditions & 10 & 1.0 \\
\hline
\end{tabular}

${ }^{1}$ Number of cases was calculated from 1-3 choices

Table 3. Respondents' perceptions of the severity of different life style components as risk factors for diabetes

\begin{tabular}{|l|c|c|}
\hline Risk factors & Mean \pm st. dev & $\begin{array}{c}95 \% \text { confidence } \\
\text { interval }\end{array}$ \\
\hline Overweight, obesity & $3.97 \pm 0.046$ & $3.88-4.06$ \\
\hline $\begin{array}{l}\text { Consuming too many } \\
\text { confectioneries }\end{array}$ & $3.63 \pm 0.050$ & $3.53-3.73$ \\
\hline Excessive fat in diet & $3.50 \pm 0.053$ & $3.39-3.60$ \\
\hline Irrational nutrition & $3.47 \pm 0.050$ & $3.37-3.57$ \\
\hline Genetic factors & $3.45 \pm 0.054$ & $3.34-3.56$ \\
\hline Older age & $3.25 \pm 0.052$ & $3.14-3.35$ \\
\hline Increased cholesterol level & $3.17 \pm 0.055$ & $3.06-3.28$ \\
\hline Low physical activity & $3.09 \pm 0.054$ & $2.98-3.19$ \\
\hline Alcohol use & $2.94 \pm 0.057$ & $2.83-3.05$ \\
\hline Increased blood pressure & $2.90 \pm 0.057$ & $2.79-3.02$ \\
\hline Substance use & $2.64 \pm 0.060$ & $2.52-2.76$ \\
\hline Smoking & $2.60 \pm 0.057$ & $2.49-2.71$ \\
\hline Highly stressful mental work & $2.36 \pm 0.055$ & $2.25-2.47$ \\
\hline Excess carbohydrates in diet & $2.36 \pm 0.057$ & $2.25-2.47$ \\
\hline Insufficient consumption of fruits & $2.34 \pm 0.053$ & $2.23-2.44$ \\
\hline Insufficient consumption of & $2.33 \pm 0.052$ & $2.22-2.43$ \\
\hline vegetables & $2.12 \pm 0.054$ & $2.01-2.23$ \\
\hline Excess proteins in diet & $2.11 \pm 0.052$ & $2.01-2.22$ \\
\hline Highly intense physical work & & \\
\hline
\end{tabular}

3 points included well know risk factors for metabolic syndrome and diabetes: being overweight, excessive sugar consumption, excess fat in diet, irrational nutrition, genetic factors, increased cholesterol, and low physical activity.

\section{Experience of Glycemic Control}

Respondents were asked whether they had previously undergone the glycemic control ("blood sugar") test. More than half of the respondents $(56.3 \%)$ responded positively and more than one third $(34.6 \%)$ negatively. The rest did not know whether or not the glycemic control test had been performed.

\section{Knowledge about the Parameters of Normal Glycemia}

The respondents were asked to indicate the lowest and highest limits of normal glycemia. The group of those knowledgeable about the normal parameters of glycemia included respondents who had mentioned at least one number falling into the normal limits of glycemia (from 3 to $6 \mathrm{mmol} / \mathrm{l}$ ).

One third of the respondents $(33.8 \%)$ knew the normal parameters of glycemia (Table 4). Women, older patients and those with higher monthly incomes had a greater awareness about this indicator. A "blood sugar" test performed at least once also related to better awareness about the limits of normal glycemia.

\section{Thoughts Associated with Diabetes and Insulin}

At least one association arising from the word "diabetes" was provided by 878 respondents $(87.6 \%)$, two associations by 140 respondents $(14.0 \%)$ and three or four associations by several respondents. There were 1,026 associations provided in total.

The respondents' perceptions of the presented words were clustered into the following groups:

Table 4. Proportion of respondents who know the normal glycemia ("blood sugar") test parameters

\begin{tabular}{|c|c|c|}
\hline Variables & $n$ & $\%$ \\
\hline \multicolumn{3}{|l|}{ Gender } \\
\hline Men & 137 & 28.3 \\
\hline Women & 202 & 39.0 \\
\hline \multicolumn{3}{|l|}{ Age groups } \\
\hline $16-24$ & 39 & 21.3 \\
\hline $25-34$ & 38 & 26.0 \\
\hline $35-44$ & 40 & 33.3 \\
\hline $45-54$ & 75 & 40.5 \\
\hline $55-64$ & 57 & 35.8 \\
\hline $65-74$ & 90 & 43.1 \\
\hline \multicolumn{3}{|l|}{ Monthly income * } \\
\hline 500 Lt or less & 27 & 18.2 \\
\hline $501-1,000 \mathrm{Lt}$ & 174 & 38.4 \\
\hline $1,001-1,500 \mathrm{Lt}$ & 61 & 38.1 \\
\hline $1,501-2,000 \mathrm{Lt}$ & 13 & 41.9 \\
\hline More than 2,001 Lt & 64 & 30.3 \\
\hline \multicolumn{3}{|c|}{ Ever had the "blood sugar" test performed } \\
\hline Yes & 282 & 47.4 \\
\hline No & 46 & 14.6 \\
\hline Don't know & 11 & 12.0 \\
\hline
\end{tabular}


- Disease (33.7\%) included perceptions such as "disease", "incurable disease" and "inherited disease".

- Patient (21.8\%) prompted the association of "severe patient" that constituted the overwhelming majority of perceptions (19.8\%), whereas the other expressions included "patient" and "sick person".

- Glycemia (16.6\%) perceptions included "a lot of sugar in the blood", "amount of sugar", "glycemic trouble", and "decreased sugar level".

- Nutrition (9.6\%) associations included "must not take sugar", "must not take confectionery", "ate too many confectioneries", "diet", "the quality of nutrition", "special nutrition", "to avoid food", and "unhealthy food", and a few said they "want to eat something sweet".

- Unbalance (6.5\%) included associations such as "something wrong", "unbalanced endocrine system", "unbalanced pancreas", "organically unbalanced", and "bad insulin level".

- Symptoms (3.6\%) included the perceptions "thirstiness", "weakness", "deteriorating vision", and "increase in weight".

- Treatment (2.3\%) associated with "medication", "injectable medication", "continuing medication", "needles", "syringes", "must approach physician", and "must follow medical recommendations".

- Complications (1.7\%) were associated with "complications", "amputation" and "coma".

- Other health problems (1.7\%) prompted the perceptions of "low haemoglobin level", "bad blood", "weak thyroid", "blood pressure", "deteriorating memory", and "liver".

- Positive approach (2.5\%) included the perceptions of "style of life" and "you can live".

The word "insulin" prompted at least one association in 845 respondents $(84.3 \%)$ and two associations in 42 respondents $(4.2 \%)$. A total of 887 associations were provided.

The following ideas were clustered into following groups regarding respondents' perceptions:

- Medication (76.7\%) included perceptions like "medication", "essential medication", "continuing use of medication", and "first aid".

- Diabetes (11.2\%) included "disease", "severe disease", "diabetes", and "chronic condition".

- Glycemic control (3.6\%) included "maintain sugar level", "regulated sugar level", "the power to assimilate glucose", "decrease sugar level", and "low sugar".

- Other health problems (3.3\%) included "stroke", "paralysis", "nervous system", "heart disease", "blood pressure", and "liver".

- The nature of insulin (3.2\%) prompted puzzling perceptions including "something like food", "alcohol", "chemical substance", "drug", and "breaks down fats".

- Complications (2\%) included "blindness", "coma", "bad health", and "handicap".

\section{DISCUSSION}

This study revealed a complex picture of the awareness the residents of Lithuania have about diabetes. The respondents in this study clearly perceived the severity of diabetes and ranked it as the fourth one among other widespread chronic conditions. It is probable that diabetes was ranked so high among the other health conditions named, because people know about diabetes and its threats to the status of health and quality of life. However, there could be other explanations for such a choice by study participants. Diabetes was ranked after the two chronic conditions that are greatly stigmatized in Lithuania - AIDS and mental illness. This study did not aim to address the issue of the potential social stigmatisation of diabetes. However, the results of the study suggest a potential social stigma of diabetes. There are no studies in Lithuania, as best as can be ascertained, addressing the issue of the potential social stigma of diabetes like in other countries (18, 19). The potential social stigmatisation of diabetes in Lithuania merits future research considering the impact of social stigma to the acceptance and management possibilities of an illness $(20,21)$.

The results of this study regarding the awareness of diabetes risk factors by its respondents also support the idea that the perception of the severity of diabetes could be affected by social stigmatisation, rather than by accurate public knowledge about this illness. Ten of the lowest ranking factors among the eighteen listed spread around the middle of the scale, ranging from $2.11 \pm 0.052$ (highly intense physical work) to $2.94 \pm 0.057$ (alcohol use). This could suggest that people were not aware of the truly important factors involved in the incidence of diabetes, e.g. an excess of carbohydrates in the diet got the same score $(2.36 \pm 0.057)$ as highly stressful mental work did $(2.36 \pm 0.055)$. Furthermore, respondents ranked substance use $(2.64 \pm 0.060)$ immediately following increased blood pressure $(2.90 \pm 0.057)$. Since all the listed components could be somehow harmful to health, it seems the study respondents simply attributed an average importance to all of them without exactly knowing which factors, in fact, indicate high risk of developing diabetes.

The highest score of all the risk factors was attributed to obesity $(3.97 \pm 0.046)$. Obesity was often recognized as the most important risk factor for developing diabetes in other studies as well (22). At first sight, this finding could suggest that the link between diabetes and obesity is quite well understood in Lithuania, in possible contrast to other study findings $(23,24)$. The significance attributed to obesity as a risk factor for diabetes was slightly higher than moderate in this study. However, obesity never emerged as a direct association with diabetes. Meanwhile the idea of "sugar" was present in one fourth of the expressed associations, meaning these associations occurred quite often. It is highly probable that diabetes links more strongly with sugar consumption in the minds of the Lithuanian population, rather than with being overweight or obese. This is in line with the findings of Kiawi et al. (25). Their study revealed that study participants from Cameroon attributed the greatest importance for causing the type 2 diabetes to excessive sugar consumption omitting excessive energy intake, physical inactivity or even obesity (25). This study also revealed that overweight and/or obesity are not terms, which people associate with the word "diabetes", at least not at the first thought. Such indirect evidence suggests that the link between obesity and diabetes might not be well understood in Lithuanian population, as already demonstrated elsewhere (23).

The experience of glycemic control in the population was rather high $(56.3 \%)$, compared with the findings of other studies (26). The fact that the glycemic test had been performed was significantly related to the better knowledge of the normal glycemia parameters. The awareness of this indicator was lowest in the group of respondents with the lowest monthly income, which was below the minimal salary. However, with the rest of the respond- 
ents, increased income did not relate to an increased knowledge of normal glycemia parameters. Opposite trends were actually observed. This finding would contradict the belief that the more affluent people have better knowledge about health related issue. Thus the relationship of affluence and knowledge concerning diabetes should be assessed in greater depth by future research.

Another insight provided by the data from this study is the marginally medicalized image of diabetes. More than half of all associations were related to the perception of diabetes as an incurable and/or inherited disease and as involving a patient with serious illness. Only $2.5 \%$ of all expressed associations with the word "diabetes" were more positive. This finding should be taken into account when tailoring public awareness campaigns related to diabetes as well as when individually approaching patients at risk for developing diabetes or even diabetic patients themselves. The existing body of research confirms that a negative self-perception of patients, their beliefs about diabetes and insulin and the impact of social stigma on psychological insulin resistance play important, though often ignored, roles in diabetes management (27). A more positive public image of diabetes among wider strata of society could reduce the fear of this disease and potentially have a favourable effect on reducing the delay between the incidence of diabetes symptoms and approaching health care providers. However, these insights need to be tested in future research.

This study has its limitations. It was cross-sectional; thus the self-generated responses were very short and sparse. The obtained qualitative data was not as rich as it could be in a qualitative survey, although the study involved a large group of respondents. Another limitation of this study was that the respondents were not asked to identify whether or not they or their family members have diabetes. Thus the study data did not allow identifying the differences in disease perception and knowledge related to diabetes and its risk factors depending on the health status of the respondents.

Despite these limitations, this study is valuable for understanding social concerns about diabetes and its risk factors in Lithuania. It revealed a picture of the foggy understanding the public have about the risk factors for developing diabetes, its much medicalized image of this disease and the potential social stigmatization of diabetes. These findings encourage searching for new ways to approach the community as well as individual diabetic patients on the issue of diabetes.

\section{Acknowledgements}

This study was financed by the Lithuanian College of General Practitioners. We would like to thank the market analysis and survey agency UAB RAIT that performed the interviews and Vijole Arbas, who provided the English editing of the manuscript.

\section{Conflict of Interests}

Alminas Jarasunas is working in Novo Nordisk Pharma UAB, Lithuania. Lina Jaruseviciene, Leonas Valius, Gediminas Jarusevicius declare no conflicts of interest.

\section{Sponsorship}

The survey was financed by the Lithuanian College of General Practitioners. We would like to thank the market analysis and survey agency UAB RAIT that performed the interviews.

\section{REFERENCES}

1. Unwin N, Whiting D, Gan D, Jacqmain O, Ghyoot G, editors. IDF diabetes atlas. 4th ed. Brussels: International Diabetes Federation; 2009.

2. Harris MI. Health care and health status and outcomes for patients with type 2 diabetes. Diabetes Care. 2000 Jun;23(6):754-8.

3. Schillinger D, Grumbach K, Piette J, Wang F, Osmond D, Daher C, et al. Association of health literacy with diabetes outcomes. JAMA. 2002 Jul 24-31;288(4):475-82.

4. Rothman R, Malone R, Bryant B, Horlen C, DeWalt D, Pignone M. The relationship between literacy and glycemic control in a diabetes diseasemanagement program. Diabetes Educ. 2004 Mar-Apr;30(2):263-73.

5. Yamashita T, Kart CS. Is diabetes-specific health literacy associated with diabetes-related outcomes in older adults? J Diabetes. 2011 Jun;3(2):13846.

6. Brega AG, Ang A, Vega W, Jiang L, Beals J, Mitchell CM, et al.; Special Diabetes Program for Indians Healthy Heart Demonstration Project. Mechanisms underlying the relationship between health literacy and glycemic control in American Indians and Alaska Natives. Patient Educ Couns. 2012 Jul;88(1):61-8.

7. von Wagner C, Knight K, Steptoe A, Wardle J. Functional health literacy and health-promoting behaviour in a national sample of British adults. $\mathrm{J}$ Epidemiol Community Health. 2007 Dec;61(12):1086-90.

8. Nutbeam D. The evolving concept of health literacy. Soc Sci Med. 2008 Dec;67(12):2072-8.

9. Dewalt DA, Berkman ND, Sheridan S, Lohr KN, Pignone MP. Literacy and health outcomes: a systematic review of the literature. J Gen Intern Med. 2004 Dec;19(12):1228-39.

10. Coffman MJ, Norton CK, Beene L. Diabetes symptoms, health literacy, and health care use in adult Latinos with diabetes risk factors. J Cult Divers. 2012 Spring; 19(1):4-9.

11. Crandall JP, Knowler WC, Kahn SE, Marrero D, Florez JC, Bray GA, et al.; Diabetes Prevention Program Research Group. The prevention of type 2 diabetes. Nat Clin Pract Endocrinol Metab. 2008 Jul;4(7):382-93.

12. Diabetes Prevention Program Research Group, Knowler WC, Fowler SE, Hamman RF, Christophi CA, Hoffman HJ, Brenneman AT, et al. 10-year follow-up of diabetes incidence and weight loss in the Diabetes Prevention Program Outcomes Study. Lancet. 2009 Nov 14;374(9702):1677-86.

13. Zhang YH, Ma WJ, Thomas GN, Xu YJ, Lao XQ, Xu XJ, et al. Diabetes and pre-diabetes as determined by glycated haemoglobin $\mathrm{A} 1 \mathrm{c}$ and glucose levels in a developing southern Chinese population. PLoS One. 2012;7(5):e37260.

14. Walker EA, Caban A, Schechter CB, Basch CE, Blanco E, DeWitt T, et al. Measuring comparative risk perceptions in an urban minority population: the risk perception survey for diabetes. Diabetes Educ. 2007 Jan-Feb;33(1):103-10.

15. Weiland TJ, Nguyen M, Jelinek GA. Illness perception and knowledge with regard to prediabetes and type 2 diabetes: a pilot study of emergency department patients and staff. Eur J Emerg Med. 2012 Dec;19(6):353-8.

16. Pinelli NR, Berlie HD, Slaughter RL, Jaber LA. Risk perception for developing diabetes among pharmacists. Ann Pharmacother. 2009 Jun;43(6):1050-6.

17. Calvin D, Quinn L, Dancy B, Park C, Fleming SG, Smith E, et al. African Americans' perception of risk for diabetes complications. Diabetes Educ. 2011 Sep-Oct;37(5):689-98.

18. Broom D, Whittaker A. Controlling diabetes, controlling diabetics: moral language in the management of diabetes type 2. Soc Sci Med. 2004 Jun;58(11):2371-82.

19. Gollust SE, Lantz PM, Ubel PA. Images of illness: how causal claims and racial associations influence public preferences toward diabetes research spending. J Health Polit Policy Law. 2010 Dec;35(6):921-59.

20. Adams OP, Carter AO. Knowledge, attitudes, practices, and barriers reported by patients receiving diabetes and hypertension primary health care in Barbados: a focus group study. BMC Fam Pract. 2011 Dec 2;12:135.

21. Tak-Ying Shiu A, Kwan JJ, Wong RY. Social stigma as a barrier to diabetes self-management: implications for multi-level interventions. J Clin Nurs. 2003 Jan;12(1):149-50.

22. Aljoudi AS, Taha AZ. Knowledge of diabetes risk factors and preventive measures among attendees of a primary care center in eastern Saudi Arabia. Ann Saudi Med. 2009 Jan-Feb;29(1):15-9.

23. Weaver NF, Hayes L, Unwin NC, Murtagh MJ. "Obesity" and "Clinical Obesity" Men's understandings of obesity and its relation to the risk of diabetes: a qualitative study. BMC Public Health. 2008 Sep 14;8:311.

24. Rosal MC, Borg A, Bodenlos JS, Tellez T, Ockene IS. Awareness of diabetes risk factors and prevention strategies among a sample of low- 
income Latinos with no known diagnosis of diabetes. Diabetes Educ. 2011 Jan-Feb;37(1):47-55.

25. Kiawi E, Edwards R, Shu J, Unwin N, Kamadjeu R, Mbanya JC. Knowledge, attitudes, and behavior relating to diabetes and its main risk factors among urban residents in Cameroon: a qualitative survey. Ethn Dis. 2006 Spring;16(2):503-9.

26. Singh A, Milton PE, Nanaiah A, Samuel P, Thomas N. Awareness and attitude toward diabetes in the rural population of Arunachal Pradesh, Northeast India. Indian J Endocrinol Metab. 2012 Mar;16 Suppl 1:S83-6.
27. Brod M, Kongsø JH, Lessard S, Christensen TL. Psychological insulin resistance: patient beliefs and implications for diabetes management. Qual Life Res. 2009 Feb;18(1):23-32.

Received June 1, 2013 Accepted in revised form September 5, 2014 